\title{
Epidemiological features of Corona Virus Disease 2019 in China
}

\author{
Ting Wang ${ }^{1}$, Qiuxin Wang ${ }^{1}$, and Jinwen Wang ${ }^{2, *}$ \\ ${ }^{1}$ School of Humanities, Jiangxi University of Traditional Chinese Medicine, Nanchang, China \\ ${ }^{2}$ School of Public Administration, Nanchang University, Nanchang, China
}

\begin{abstract}
As a public health emergency with strong infectious, corona virus disease (COVID-19) in Wuhan,Hubei in December 2019 has attracted worldwide concern. The epidemiological features of COVID19 in China at the early stage are examined. The spread of COVID-19 has reached a peak in China. The epidemic situation is very severe, especially in the regions or central cities closely linked with Wuhan. The increase in cure rate of COVID-19 also predicts a reduction in the risk of fatality.
\end{abstract}

\section{Introduction}

On February 11, 2020, The World Health Organization (WHO) named the pneumonia caused by the new coronavirus (2019-nCoV) as "corona virus disease (COVID-19)". As COVID-19 continues to threaten global health, it has attracted international attention[1]. WHO announced COVID-19 was listed as a public health emergency (PHEIC) of international concern[2].

At first, the disease was thought to be related to the South China Wuhan seafood market. The symptoms of the patients are mainly fever, diarrhea and so on. After that, the study found that the virus can spread through droplets, aerosol transmission, contact transmission and so on. [3-12]. On January 25, a team found medicines, active natural products and traditional Chinese medicine may had a therapeutic effect on COVID-19[10]. After a few days, a case of pneumonia in the United States was treated with Remdesivir and showed significant improvement[11], Remdesivir is currently in clinical trials.

Although the past two centuries have seen enormous achievements in control of infectious diseases, the prevalence of Infectious Diseases, especially in developing countries, is still a tremendous challenge to public health authorities[13]. For example, SARS, which was endemic in China, caused irreparable damage in China and even around the world in 2003[14]. As of February 12, the number of confirmed cases of COVID-19 was seven times that of SARS in 2003[15], the situation shows that the continued epidemic of COVID-19 may be much higher than SARS[16]. In addition, the cost of preventing infectious diseases in advance was much lower than that of treating them[17].

Along with the number of confirmed cases was rising nationally, COVID-19 spread rapidly from Wuhan to other provinces and cities in China. Since the incubation period of the new coronavirus is about 2 weeks[18], if the epidemic is not well controlled, the Chinese government and people will face great challenges. Therefore, according to the latest data, analyzing the epidemiological characteristics of COVID-19 in China is necessary and urgent.

\section{Method}

Use Office Excel 2019 and Adobe Photoshop CS6 to draw the relevant charts and maps, including number of confirmed cases, fatal cases, new cases, and suspected cases and so on. All data for COVID-19 from January 11, 2020 to February 12, 2020 were provided from public data by the National Health Commission of the People's Republic of China, the Municipal Health Commission in 31 provinces, and official channels in Hong Kong, Macao and Taiwan (34 regions).

\section{Results}

\subsection{COVID19 in China}

The peak period of outbreak had being appeared in the early Feb, 2020, but inflection point of decrease didn't appear. From Figure 1, we found that the number of confirmed, deaths and new cases of COVID-19 continually increased rapidly per day in China from January 11, 2020 to February 12, 2020 (41, 1 and 0 on January 11;59882, 1368 and 15153 on February 12 respectively). Without any suspense, there was the largest number of confirmed cases $(\mathrm{N}=48,206)$ in Hubei Province. The rate of increase of confirmed cases from Feb 1, 2020 to Feb 12, 2020 was higher than that from Jan 11, 2020 to Jan 31, 2020, and the highest number $(\mathrm{N}=15153)$ of new cases occurred in Feb 12, 2020. As of 24:00 on Feb 12, the number of confirmed cases has increased by 402 times in the 33 day period, which showed a sharp peak in the process of continuous rise.

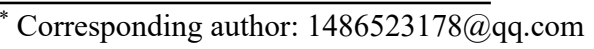




\subsection{Regional differences of COVID-19}

A total of 34 regions were included in this study, including mainland China, Hong Kong, Macao and Taiwan. According to the data of the confirmed cases, we pictured the geographical distribution map to display the regional difference of COVID-19 prevalence in China (Figure 1). As seen from the figures, the epidemic was centered in Wuhan, Hubei province and spread rapidly to all provinces and cities around the country. No province was spared, especially those regions with close relationship with Wuhan metropolitan area, developed transportation and large population mobility had witnessed rapid growth of confirmed cases, though the incidence cases in other provinces was much lower than that in Hubei province. In addition to Hubei, Guangdong, Henan and Zhejiang provinces also confirmed more than 1,000 cases as of Feb. 12 (Figure 2).
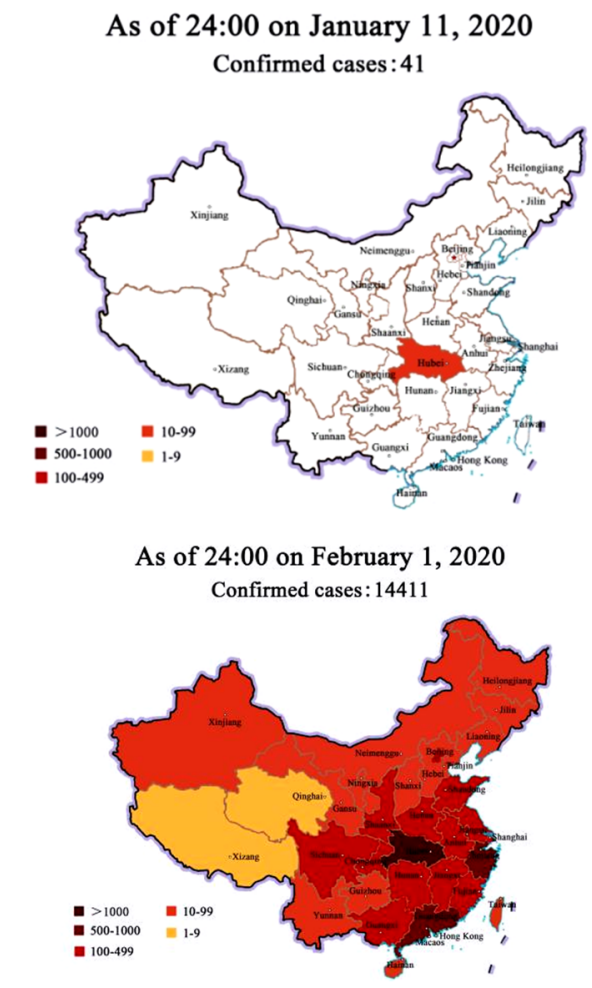

As of 24:00 on February 12, 2020 Confirmed cases : 59882

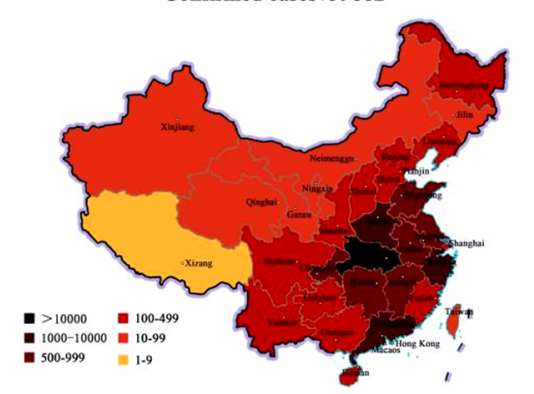

Figure 1. Confirmed cases on January 11, February 1 and February 12

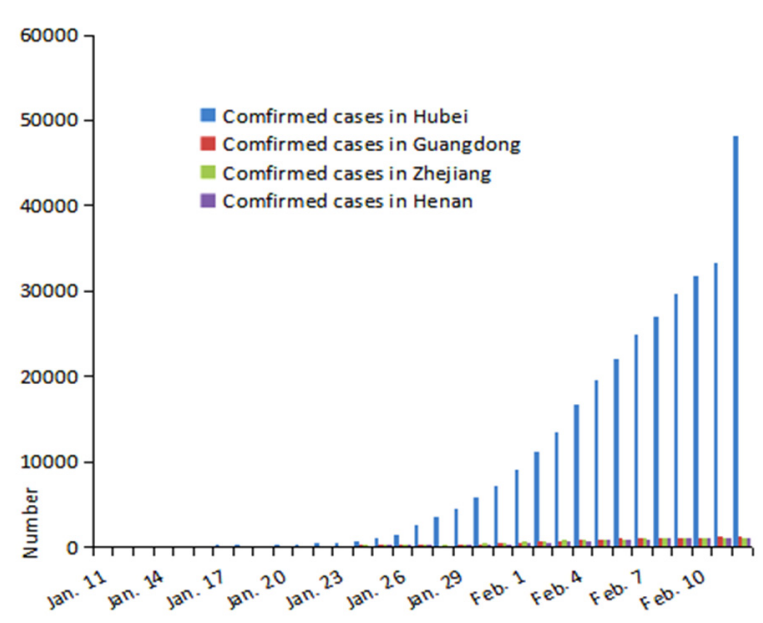

Figure 2. Confirmed cases among Hubei, Guangdong, Henan and Zhejiang province

Moreover, through the comparison of the doubling rate of confirmed cases in Guangdong, Zhejiang, Henan and Hubei, we found that after the surge of confirmed cases in the early stage of the outbreak, the development pattern of the epidemic tends to be similar to that of Hubei Province. In general, there was a slight increase in the early stages of the epidemic, and it slowly declined from to 1 after reaching the peak and gradually down (Figure $3)$.

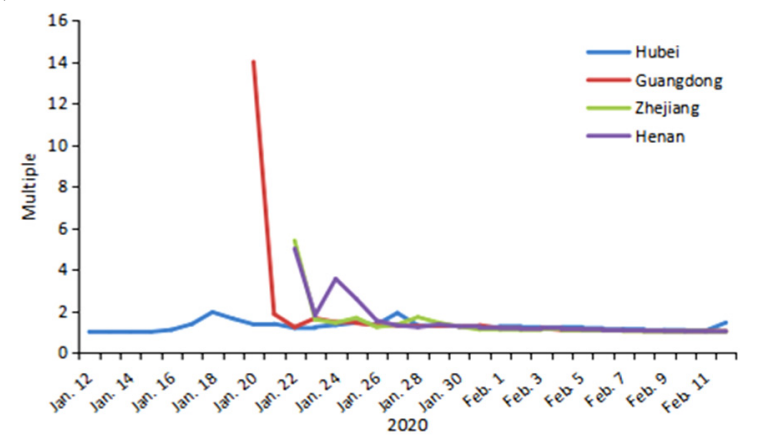

Figure 3. Multiple of confirmed cases over time among Hubei, Guangdong, Henan and Zhejiang

As can be seen from Figure 4 and 5, the fatality rate of COVID-19 decreased gradually after experiencing a small peak at an early stage, and there were obvious regional, age and sex differences in fatality. Based on the data of Feb. 12, 2020, the fatality rate was 228 cases/10,000 individuals $(2.28 \%)$ in China, 272 cases $/ 10,000$ individuals (2.72\%) in Hubei Province, but the fatality rate outside Hubei was only 50 cases/10,000 individuals $(0.50 \%)$. To research the age differences of COVID-19 fatality, we divided the cases into six groups: 0-40 years old, 40-50 years old, 50-60 years old, 60-70 years old, 70-80 years old, and 80-90 years old. The results indicated that senior group (Age $>60)$ had a higher fatality rate than the younger group $(0<$ Age $<60)$. Moreover, the results showed COVID-19 deaths in male cases were higher than female cases.

The cure rate of COVID-19 rose rapidly after a low point, which was higher than the fatality rate for 11 consecutive days (Figure 5). The incidence of fatality continually decreased from the highest point in Jan 16, $2020(4.44 \%)$ to the lowest point in Jan 19, $2020(1.51 \%)$, and incidence of cure was significant higher than fatality 
from Feb 1, 2020 to Feb 12, 2020 (Table 1). The average incidence of cure was 2.64 times higher than that of fatality from Feb 1, 2020 to Feb 12, $2020(5.73 \%$ vs $2.17 \%$, $\mathrm{IRR}=2.64$ ).

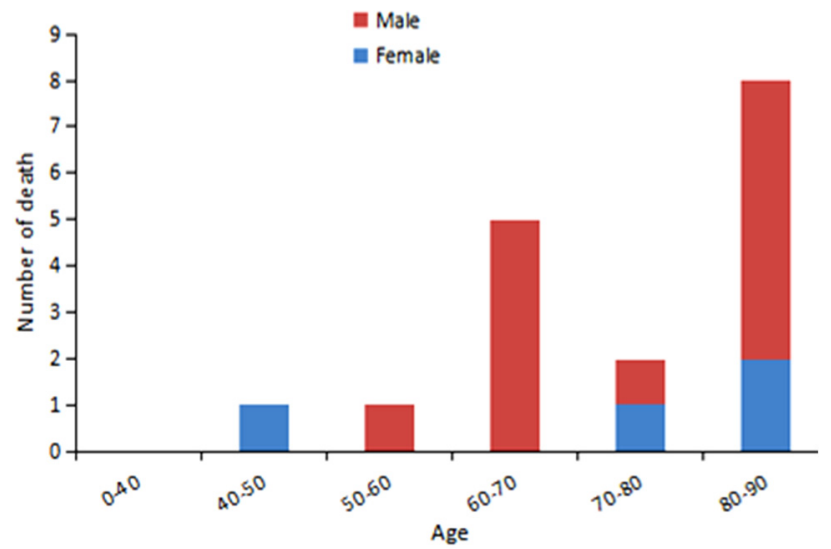

Figure 4. Difference of COVID-19 fatality in sex and age

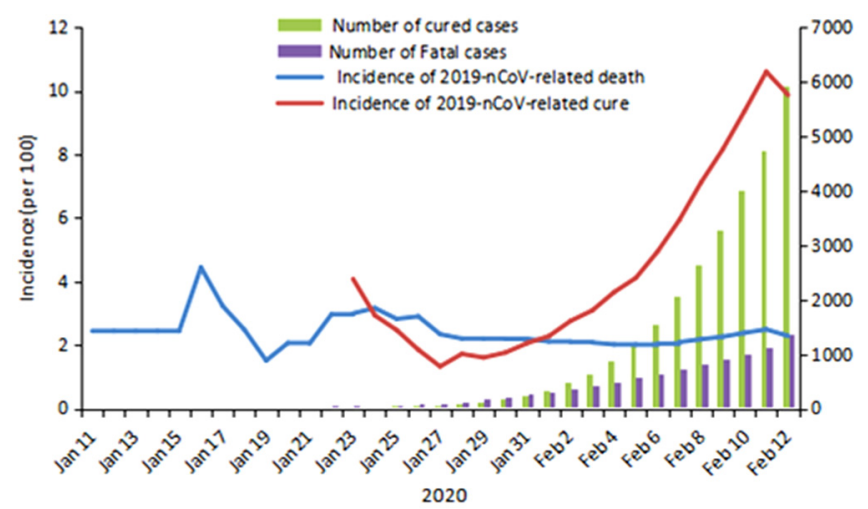

Figure 5. Incidence of COVID-19 related death and cure

Table 1. The differences in the number of cures and the deaths (Feb 1 to 12).

\begin{tabular}{cccc}
\hline Variable & Mean & $\mathrm{T}(95 \% \mathrm{CI})$ & $\begin{array}{c}\mathrm{P}- \\
\text { value }\end{array}$ \\
\hline $\begin{array}{c}\text { the } \\
\text { number } \\
\text { of cures }\end{array}$ & 2304.92 & $2.937(463.787,2691.879)$ & $<0.01$ \\
\hline
\end{tabular}

\section{Discussion}

According to the latest official data, the number of confirmed, suspected and cases of COVID-19 continually increased rapidly in the early Feb, 2020, which indicated that the peak period of outbreak had being appeared, but inflection point of decrease didn't appear. The analysis showed that the epidemic was centered in Wuhan, Hubei province and spread nationally during the early stage, though the incidence cases and death rate in other provinces was much lower than that in Hubei province.

After a wide range of patients were admitted, the data may look scary, but it makes it less likely that potential spreaders will travel and create new ones. Some studies using mathematical model that predict the number of confirmed cases of COVID-19 predict that the number of confirmed cases of COVID-19 will be very high in China, and Wuhan will be much larger than other Chinese cities, but the reality is different. The number of confirmed cases in various provinces and cities increased exponentially over time, but the number of confirmed cases in Wuhan did not reach more than 20,000 on January 23, 2020, as predicted[19-20]. Although the situation is not as severe as predicted, the overall growth is doubling down, but this just reflects the difficulty of COVID-19 prediction and prevention. It may be because the government's prevention and control efforts are getting stronger, and residents' awareness of protection is getting stronger. COVID-19 has been diagnosed in more people than SARS, and has increased at a faster rate, but has a lower fatality rate[21].

Understanding the speed and patterns of transmission is essential for successful disease control[22]. With Wuhan, Hubei province as the center, COVID-19 spread rapidly to the whole country. Near the Spring Festival, many people go home or travel abroad, which will spread COVID-19 to a large extent[24-25]. In the early days of $\mathrm{NCP}$, the rate of spread in other provinces and cities was much lower than in Hubei, either because of increased government control or because of a small infection base in other provinces and cities. If COVID-19 is not controlled, China and the world will be threatened[26].

The results showed the epidemic development mode in other regions tended to be similar to Hubei, which indicated that the regions with close relationship with Wuhan metropolitan area, developed transportation and large population mobility faced great threat. At present, Chinese urbanization has entered a stage in which the central cities drive the urban agglomerations and then drive the regional economic development. Compared with the SARS in 2003, the characteristics of population agglomeration in spatial structure are as follows: the population of central cities and urban agglomerations accelerate agglomeration. Chinese 19 urban agglomerations account for $75 \%$ of the country's population. Along with the developed transportation infrastructure, especially the high-speed rail, the scale of population mobility in China is about six times that of 17 years ago. Now it is the peak flow of returning to work after the Spring Festival in China. In terms of the relationship between the urban agglomerations and Wuhan metropolitan area, the epidemic threat of Wuhan metropolitan area and the urban agglomerations in the middle reaches of the Yangtze River, the Yangtze River Delta, Beijing Tianjin Hebei, Guangdong, Hong Kong, Macao and Chengdu Chongqing is particularly serious. With a large number of people returning to work after the Spring Festival, Beijing, Shanghai, Nanjing, Hangzhou, Shenzhen, Guangzhou, Chengdu, Chongqing, Changsha, Hefei, etc. will face a severe test in the next four weeks.

Since January 27, the fatality rate of COVID-19 had steadily decreased, and a few days later, the number of cured cases had gradually exceeded the number of deaths. Scholars such as Joseph T Wu predicted the spread of the COVID-19 across the country based on the number of existing cases. They estimated that Wuhan epidemic would reach its peak around April 2020, and other cities in China would postpone for a week or two 19. But the latest data showed that the COVID-19 infection peaked in February 2020. It was explain that the effect of disease 
treatment has been greatly improved. Currently, there is no vaccine to treat COVID-19, and the drug treatment options include three scientific and targeted methods. Especially some traditional Chinese medicines such as Lianhuaqingwen Capsule and Shuanghuanglian Oral Liquid may suppress COVID-19[27], and they were still in clinical testing. The symptoms of COVID-19 were very similar to SARS-CoV and MERS-CoV, such as fever, dyspnoea and so on[28-29]. The majority of patients who die from COVID-19 and MERS-CoV were male patients. But patients who die from MERS-CoV were younger than those of COVID-19. It could be seen that the treatment effect is better [30].

In this study, there are some limitations. Currently, the date of COVID-19 population in China cannot be collected, due to the lack of medical facilities, some suspected cases were not diagnosed in time. Therefore, there is still a certain deviation in this research. In addition, because of the insufficient public data in the study, we cannot analyze other risk factors. For instance, occupations, medical environment, and underlying diseases, and these maybe all the risk factors for fatality. In spite of this, the following conclusions can be drawn from such a large sample, COVID-19 varies by region, age and sex. A well-planned and effectively communicated were important strategy,[31] the Chinese government should continue to publicize and take more effective prevention measures to reduce the spread of COVID-19 .

\section{Conclusions}

Our results of large-scale epidemiological research showed that COVID-19 patients were increasing every day and reached the peak period recently, and gradually spread across the country. COVID-19 is putting the whole country on alert. The rapid rise and development trend of COVID19 epidemic in other regions tends to be similar to Hubei Province, predicting a great threat and challenge not only to Hubei, but also to the regions with large population flow, especially to central cities. At the same time, the number of cured cases has gradually exceeded the number of deaths, and predicts a reduction in the risk of fatality. Our findings can provide some information for prevention and control of COVID-19, and will help governments allocate resources rationally and limit the spread of COVID-19.

\section{Acknowledgements}

This research was financially supported by Jiangxi Social Science Foundation Project of China(20JY20) and Jiangxi Provincial planning of educational science general project of China (19YB015)

\section{References}

1. WHO. Emergencies preparedness, response. Pneumonia of unknown origin-China. Disease outbreak news. 5 January, (2020), https://www.who.int/csr/don/05-january-2020pneumonia-of-unkown-cause-china/en/; 2020 [Accessed 30 Jan 2020].
2. WHO. Emergencies preparedness, response. 2019nCoV - China. Disease outbreak news. 30 January, (2020), https://www.who.int/csr/don/12-january2020-novel-coronavirus-china/en/; 2020 [accessed 12 Jan 2020].

3. Chen N, Zhou M, Dong X, et al. Epidemiological and clinical characteristic of 99 cases of 2019 novel coronavirus pneumonia in Wuhan, China: a desc riptive study [J]. The Lancet, (2020). https://doi.org/10.1016/S0140-6736(20)30211-7.

4. Huang C, Wang Y, Li X, et al. Clinical features of patients infected with 2019 novel coronavirus in Wuhan, China[J]. The Lancet, (2020). https://doi.org/10.1016/S0140-6736(20)30183-5.

5. Report of clustering pneumonia of unknown etiology in Wuhan City. Wuhan Municipal Health Commission, (2019).

(http://wjw.wuhan.gov.cn/front/web/showDetail/201 9123108989).

6. Chan J F W, Yuan S, Kok K H, et al. A familial cluster of pneumonia associated with the 2019 novel coronavirus indicating person-to-person transmission: a study of a family cluster[J]. The Lancet, (2020). https://doi.org/10.1016/S01406736(20)30154-9.

7. Report of Viral pneumonia of unknown origin in Wuhan City. Wuhan Municipal Health Commission, http://wjw.wuhan.gov.cn/front/web/showDetail/; (2020) [accessed 6 February 2020].

8. Zhu N, Zhang D, Wang W, et al. A novel coronavirus from patients with pneumonia in China, 2019[J]. New England Journal of Medicine, (2020). https://doi.org/10.1056/NEJMoa2001017.

9. Khan S, Ali A, Siddique R, et al. Novel coronavirus is putting the whole world on alert [J]. Journal of Hospital Infection, https://doi.org/10.1016/j.jhin.2020.01.019.

(2020).

10. A joint research team from the Shanghai institute of materia medica of the Chinese academy of sciences and the university of science and technology ofShanghai has identified a batch of old and traditional Chinese medicines that may have a therapeutic effect on the new type of pneumonia. Shanghai Institute of Materia Medica, Chinese Academy of Sciences, (2020), http://www.simm.cas.cn/xwzx/kydt/202001/t20200 125_5494417.html [accessed 7 February 2020].

11. Holshue M L, DeBolt C, Lindquist S, et al. First Case of 2019 Novel Coronavirus in the United States[J]. New England Journal of Medicine, (2020). https://www.nejm.org/doi/pdf/10.1056/NEJMoa200 1191.

12. National Health Commission of the People's Republic of China. Guidelines of prevention and Route of transmission of 2019-nCoV. http://www.nhc.gov.cn/jkj/s3578/202001/9e730600 17d744aeafff8834fc0389f4.shtml?spm=C73544894 212.P26997653879.0.0/; 2020 [accessed 08 February 2020]. 
13. Schlipköter U, Flahault A. Communicable diseases: achievements and challenges for public health[J]. Public Health Reviews, (2010), 32(1): 90. https://doi.org/10.1007/BF03391594.

14. Liu C. The battle against SARS: a Chinese story[J]. Australian Health Review, (2003), 26(3): 3-13. The battle against SARS: a Chinese story. doi: https://doi.org/10.1071/AH030003.

15. WHO. Summary of probable SARS cases with onset of illness from 1 November 2002 to 31 July 2003, https://www.who.int/csr/sars/country/table2004_04_2 1/en/; 2003 [accessed 06 February 2020].

16. Liu T, Hu J, Kang M, et al. Transmission dynamics of 2019 novel coronavirus $(2019-\mathrm{nCoV})[\mathrm{J}]$. bioRxiv, (2020).

doi: https://doi.org/10.1101/2020.01.25.919787.

17. Miller T L, McNabb S J N, Hilsenrath P, et al. The societal cost of tuberculosis: Tarrant County, Texas, 2002[J]. Annals of epidemiology, (2010), 20(1): 1-7). Therefore, the research, control and prevention of covid-19 are not only imminent, but also reasonable and reduce the waste of resources. https://doi.org/10.1016/j.annepidem.2009.09.004.

18. New suspected cases continue to decline, "Fighting infectious diseases" still need to tighten. People's Daily online, http://yuqing.people.com.cn/n1/2020/02 06/c209043-31573788.html; (2020) [accessed 7 Febrary 2020].

19. Wu J T, Leung K, Leung G M. Nowcasting and forecasting the potential domestic and international spread of the 2019-nCoV outbreak originating in Wuhan, China: a modelling study[J]. The Lancet, (2020). https://doi.org/10.1016/S01406736(20)30260-9.

20. Kucharski A J, Russell T W, Diamond C, et al. Early dynamics of transmission and control of 2019-nCoV: a mathematical modelling study[J]. medRxiv, (2020). doi: https://doi.org/10.1101/2020.01.31.20019901.

21. Zhou T, Liu Q, Yang Z, et al. Preliminary prediction of the basic reproduction number of the Wuhan novel coronavirus 2019-nCoV[J]. arXiv preprint arXiv:2001.10530, (2020).

22. Ditsuwan T, Liabsuetrakul T, Chongsuvivatwong V, et al. Assessing the spreading patterns of dengue infection and chikungunya fever outbreaks in lower southern Thailand using a geographic information system[J]. Annals of epidemiology, (2011), 21(4): 253261. https://doi.org/10.1016/j.annepidem.2010.12.002.

23. Chinazzi M, Davis J T, Gioannini C, et al. Preliminary assessment of the International Spreading Risk Associated with the 2019 novel Coronavirus (2019$\mathrm{nCoV})$ outbreak in Wuhan City $[\mathrm{J}]$. (2020). https://www.apprise.org.au/wpcontent/uploads/2020/01/ChinazziCIDID20_nCVExportation.

24. Center for Disease Control of Prevention. First travelrelated case of 2019 novel coronavirus detected in United States: press release, Tuesday, January 21, (2020), https://stacks.cdc.gov/view/cdc/84535/; 2020 [accessed 06 February 2020].

25. Booth T F, Kournikakis B, Bastien N, et al. Detection of airborne severe acute respiratory syndrome (SARS) coronavirus and environmental contamination in SARS outbreak units[J]. The Journal of infectious diseases, (2005), 191(9): 14721477. https://doi.org/10.1086/429634.

26. Riou J Y, Althaus C. Pattern of early human-tohuman transmission of Wuhan 2019 novel coronavirus (2019-nCoV), December 2019 to January 2020[J]. Eurosurveillance, (2020), 25(4): pii $=$ 2000058 . https://doi.org/10.1101/2020.01.23.917351.

27. Lu H. Drug treatment options for the 2019-new coronavirus (2019-nCoV)[J]. BioScience Trends, (2020). doi: https://doi.org/10.5582/bst.2020.01020.

28. Lee $\mathrm{N}$, Hui D, Wu A, et al. A major outbreak of severe acute respiratory syndrome in Hong Kong[J]. New England Journal of Medicine, (2003), 348(20): 1986-1994. doi: 10.1056/NEJMoa030685.

29. Assisi A, Al-Tawfiq J A, Al-Rabeeah A A, et al. Epidemiological, demographic, and clinical characteristics of 47 cases of Middle East respiratory syndrome coronavirus disease from Saudi Arabia: a descriptive study[J]. The Lancet infectious diseases, (2013), 13(9): 752-761. https://doi.org/10.1016/S1473-3099(13)70204-4.

30. Hui D S, Azhar E I, Kim Y J, et al. Middle East respiratory syndrome coronavirus: risk factors and determinants of primary, household, and nosocomial transmission[J]. The Lancet Infectious Diseases, (2018), $\quad \mathbf{1 8 ( 8 ) :}$ e217-e227. https://doi.org/10.1016/S1473-3099(18)30127-0.

31. Yen M Y, Chiu A W H, Schwartz J, et al. From SARS in 2003 to H1N1 in 2009: lessons learned from Taiwan in preparation for the next pandemic $[\mathrm{J}]$. Journal of Hospital Infection, (2014), 87(4): 185-193. https://doi.org/10.1016/j.jhin.2014.05.005 